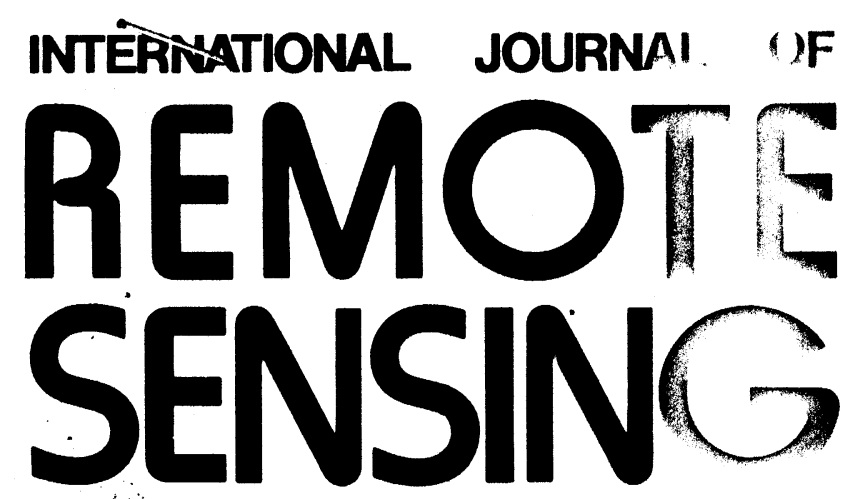

Volume 17 Number $4 \quad 10$ March 1996

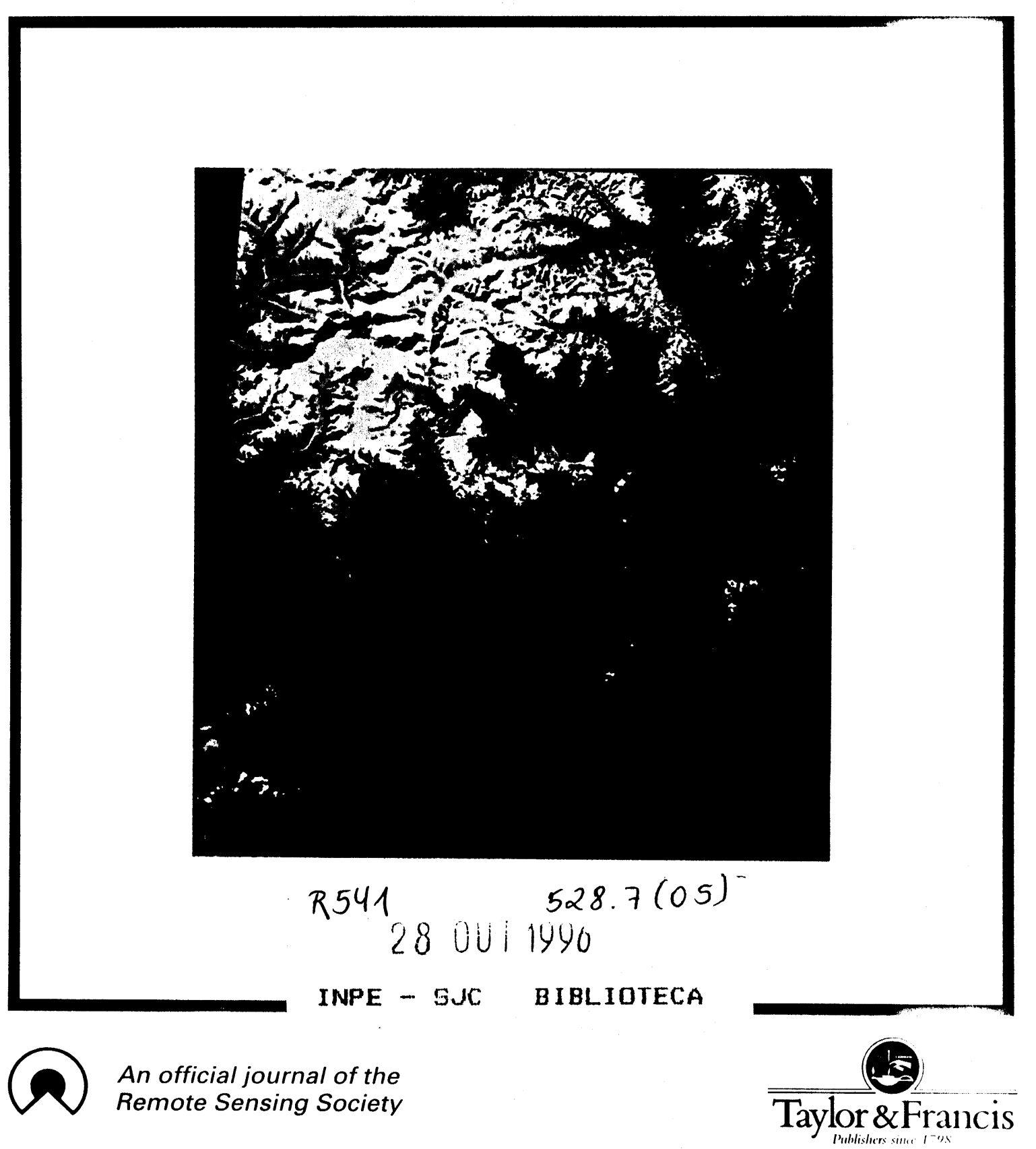




\title{
Characterizing land cover dynamics using multi-temporal imagery
}

\author{
D. S. ALVES \\ Instituto Nacional de Pesquisas Espaciais (INPE), Av. dos Astronautas 1758, \\ C.P. 515, CEP 12201-970, São José dos Campos, SP, Brazil

\section{and D. L. SKOLE} \\ Complex Systems Research Center, Institute for the Study of Earth, Oceans \\ and Space, University of New Hampshire, Durham, NH, 03824, U.S.A.
}

(Received 28 March 1995; in final form 20 September 1995)

\begin{abstract}
An analysis of land cover changes was performed using a time-series of five SPOT HRV images for an area of the State of Rondonia (western Brazilian Amazon) from 1986 to 1992 . The total deforested area and the fraction of land abandoned to secondary vegetation were determined by means of image classification and Geographical Information System (GIS) techniques. Areas deforested by 1986 were traced throughout the period to estimate the fraction of land remaining continuously in the secondary vegetation category, possibly forming older secondary vegetation.
\end{abstract}

\section{Introduction}

Human-induced changes in land cover influence the global carbon cycle, and contribute to the increase in atmospheric $\mathrm{CO}_{2}$. According to Schimel et al. (1995). land cover changes during the $1980 \mathrm{~s}$ resulted in average net emissions of $1.6 \pm 1.0 \times 10^{15} \mathrm{gCy}^{-1}$ in the tropics and an average net uptake of $0.5 \pm 0.5 \times 10^{15} \mathrm{gC} \mathrm{y}^{-1}$ from Northern Hemisphere forest regrowth. The uncertainties of these estimates can be attributed to the scarcity of reliable data on rates of land cover changes and on biomass spatial distribution.

Satellite sensor imagery has helped to increase the accuracy with which tropical deforestation can be mapped, particularly in the Brazilian Amazon (Tardin et al. 1980, Alves et al. 1992, INPE 1992, Martini 1992, Skole and Tucker 1993 , Chomentowski et al. 1994). However, the rôle of forest regrowth as a carbon sink is still poorly quantified (Schimel et al. 1995), despite a number of studies that use remotely sensed data to assess secondary vegetation regrowth (Brondizio et al. 1993, Lucas et al. 1993, Moran et al. 1993, Skole et al. 1994).

This Letter presents an analysis of land cover changes over an area in Rondônia State (western Brazilian Amazon) from 1986 to 1992, based on a time-series of SPOT HRV data. The work was aimed at assessing secondary vegetation regrowth in a region of the typical Rondônia 'fish-bone' occupation, to provide subsidies for more comprehensive land cover change analyses.

The total deforested area and the fraction of land abandoned to secondary vegetation (inside the deforested area) are determined by using digital image classification and Geographical Information System (GIS) techniques for five different years $(1986,1988,1989,1991$ and 1992). Areas deforested by 1986 were traced 
throughout the study period to estimate the fraction of land remaining continuously in the secondary vegetation category, possibly forming older secondary vegetation.

\section{Study area}

The study area is located in the State of Rondônia (western Brazilian Amazon) between the Jamari and the Candeias Rivers, close to the town of Ariquemes and the BR-364 highway. It is $43 \mathrm{~km} \times 49 \mathrm{~km}$ and has a total area of $210884 \mathrm{ha} \mathrm{(} 1 \mathrm{ha}=$ $10^{4} \mathrm{~m}^{2}$ ). Its boundaries correspond to the overlapping area of the five images used in the study $(\mathrm{K}=675, \mathrm{~J}=369$, dated 23 August 1986, 7 October 1988, 24 August 1989, 30 July 1991 and 2 August 1992), with approximate centre coordinates of $9^{\circ} 37^{\prime} \mathrm{S}$ and $63^{\circ} 22^{\prime} \mathrm{W}$.

The native vegetation consists of dense tropical forest covering a slightly undulated terrain (RADAMBRASIL 1978). Small, isolated areas of savannas, grasslands and alluvial vegetation can also be found in the region and are visible on SPOT and Landsat Thematic Mapper (TM) imagery.

Human occupation in the area has considerably increased since the mid 1970s. The majority of the properties are relatively small (40-100 ha, E. Matricardi, personal communication 1995) and are scattered along secondary roads that emerge from the major arteries, creating the typical Rondônia 'fish-bone' pattern. Most of the settlements were established in recent years, the Landsat Multi-Spectral Scanner (MSS) image dated 7 July 1973 showing less than 800 ha of deforested land in the area.

A visit to the region showed that the land is predominantly occupied by pastures, although areas of perennial cultures like cacao and coffee can be found. Part of the deforested land is abandoned, possibly due to the lack of capital for further land development or for maintaining a plantation when crop prices fall. Abandonment of the land results in secondary vegetation regrowth.

\section{Methods}

The analysis was performed using digital image processing and GIS techniques. The images were initially read from digital tapes and co-registered. The processing of the data consisted of three major steps: (1) identification of the total deforested area; (2) identification of the areas of secondary vegetation; and (3) analysis of land cover dynamics.

The first step consisted of delimiting the total deforested area, including areas of use and areas of secondary vegetation. It was initiated with a maximum likelihood classifier, with training sets representing the different types of land use and regrowth stages. Classification results were filtered to eliminate isolated pixels and classification errors were corrected by manual editing. This editing consisted of delimiting the areas erroneously classified and redefining their classes using image combination by logical operators (a major source of error was the confusion between savannas and pastures and between secondary and alluvial vegetation, that were separated by this procedure).

To simplify the processing, the analysis started with the 1992 image; the 1992 total deforested area was subsequently used as a mask, and the classification of previous years was confined to its limits. Results for every image were attentively revised for error identification and correction.

Some areas of older secondary vegetation had to be treated separately because they could be successfully separated from forests only in the 1986 image. These areas 
were delineated in the 1986 image and then incorporated into the total deforested area by a logical operator.

The results of the first step are five maps of the total deforested areas of the 1986. 1988, 1989, 1991 and 1992 images.

The second step consisted in separating the areas of secondary vegetation within the deforested areas for each image. A revision of the areas classified as secondary vegetation was separately performed, consisting of image filtering, manual editing and visual inspection, as in step 1 . Secondary vegetation was confined to the total deforested area of the corresponding image.

Five maps were produced as a result, each one characterizing the areas of secondary vegetation for one image. At the end of step 2 it was possible to estimate the fraction of secondary vegetation for each year.

The aim of the analysis of land cover dynamics (step 3) was to trace the evolution of the area deforested by 1986 in order to assess the fraction of the 1986 secondary vegetation that was preserved over the years.

The maps generated in steps 1 and 2 were combined by logical operators to identify the areas classified as secondary vegetation in 1986 and 1988; then in 1986. 1988, 1989 and 1991; and, finally, the areas classified as secondary vegetation in every image. Additionally, the fraction of the original 1986 deforested area where no secondary vegetation was observed over the years was similarly determined.

\section{Results and discussion}

The data originated from steps 1 and 2 above are shown in Table 1. An average annual rate of deforestation of 3065 ha year $^{-1}$ (1.5 per cent of the study area) can be calculated from these data.

The results show that the deforestation rates varied from year to year, with a possible maximum between 7 October 1988 and 24 August 1989. The fraction of secondary vegetation was the lowest in 1986 , increasing significantly afterwards. This shows that the factors that influence human occupation in the region may change relatively fast, affecting both the rates of clearing and abandonment. The data also indicate that the fraction of land abandoned to secondary vegetation can rise at the same time as new areas are cleared.

Although the aim of this work was not to precisely delimit individual properties. visual analysis of the maps suggests that the deforested area has increased largely due to the clearing of small areas.

The results also indicate that the deforestation rates in the study area for the

Table 1. Deforested area

\begin{tabular}{lccc}
\hline & \multirow{2}{r}{$\begin{array}{c}\text { Total } \\
\text { Image }\end{array}$} & \multicolumn{2}{c}{$\begin{array}{c}\text { Secondary } \\
\text { vegetation }\end{array}$} \\
\cline { 3 - 4 } date & area (ha) & area (ha) & $(\% \dagger)$ \\
\hline 23 Aug 1986 & 28890 & 6365 & 22 \\
7 Oct 1988 & 35484 & 17064 & 48 \\
24 Aug 1989 & 39797 & 15404 & 39 \\
30 Jul 1991 & 43914 & 17321 & 39 \\
2 Aug 1992 & 47282 & 20068 & 42 \\
\hline
\end{tabular}

$\dagger$ Percent of the total deforested area 
period were higher than those obtained by INPE (1992) for the entire State $(0.9$ per cent year ${ }^{-1}$ for the $1978-1989$ period, 0.6 per cent year $^{-1}$ for 1988-1991, and 0.4 per cent year ${ }^{-1}$ for $\left.1990-1991\right)$. The higher deforestation rates in the study area may illustrate the importance of the BR364 highway to stimulate new settlements in Rondônia.

The data generated in step 3 are presented in table 2 . Table $2(a)$ shows that the 1986 secondary vegetation areas were partially depleted over the years. Nonetheless. results show that up to 42 per cent of this area may have remained abandoned from 1986 to 1992 . Conversely, 55 per cent of the 1986 areas that had no secondary vegetation were abandoned during the period (table $2(b)$.

These results show that abandonment is an important practice in the region. They also confirm that secondary vegetation may be, as detected in other studics (Moran et al. 1993, Skole et al. 1994), an important source of land for clearing in Brazilian Amazonia. At the same time, the data allowed the identification of areas where older stages of secondary vegetation may be developing.

In this study some areas of secondary vegetation could be successfully separated from forests only in the 1986 image, probably before they attained older stages of regrowth. Moreover, some areas of cacao plantations could not be successfully separated from secondary vegetation, which may indicate a limitation of the technique.

\section{Conclusions}

Results indicate that SPOT HRV data can increase the accuracy with which land cover changes can be measured as a prerequisite to a study of the carbon balance. Particularly, the use of SPOT HRV multi-temporal imagery might help not only in deforestation rate assessments, but also in the characterization of areas of secondary growth. Results indicate that the data generated useful results under the conditions of the 'fish-bone' occupation of Rondônia.

The results suggest that secondary vegetation is partially cleared after some time. However, the total pool of secondary vegetation increased over time, increasing carbon uptake. Abandonment increased faster than clearing, probably causing uptake to grow faster than gross emissions.

High rates of carbon accumulation by secondary forests occur during the first 20 years of forest growth (Brown and Lugo 1990). Hence, a more definite contribution to carbon cycle studies could still rely on remotely sensed data but would require

Table 2. Evolution of 1986 deforested area.

(a) Area of persisting secondary vegetation.

\begin{tabular}{ccc}
\hline & \multicolumn{2}{c}{ Secondary vegetation } \\
\cline { 2 - 3 } Year & (ha) & $(\% \dagger)$ \\
\hline 1986 & 6365 & 22 \\
1988 & 4827 & 17 \\
1989 & 3755 & 13 \\
1991 & 2997 & 10 \\
1992 & 2678 & 9 \\
\hline
\end{tabular}

$\lceil$ Percent of 1986 total deforested area (b) Area with no occurrence of secondary vegetation.

\begin{tabular}{ccc}
\hline & \multicolumn{2}{c}{ No secondary vegetation } \\
\cline { 2 - 3 } Year & (ha) & (\% $\ddagger)$ \\
\hline 1986 & 22525 & 79 \\
1988 & 13383 & 46 \\
1989 & 12107 & 42 \\
1991 & 11046 & 38 \\
1992 & 10046 & 35 \\
\hline
\end{tabular}

$\ddagger$ Percent of 1986 total deforested area 
the analysis of imagery for longer periods of time. This could be done, in several cases, by accessing Landsat MSS datasets for the 1970s.

The results presented here are still preliminary. Further work requires more extensive field work and better algorithms for image classification, particularly to investigate the discrimination of secondary vegetation, forest and some types of plantations.

\section{Acknowledgments}

This study was made possible by the support of the Complex Systems Research Center, University of New Hampshire, while the first named author was visiting that Center. The authors would like to thank W. Chomentowski, Bill Salas (UNH). A. Nobre (INPA), G. Batista, T. Krug, J. Soares, D. Valeriano and C. Yanasse (INPE) for their comments and suggestions. Support for this project is also being provided by the National Research Council (CNPq).

\section{References}

Alves, D. S., Meira Filho, L. G., D’Alge, J. C. L., Mello, E. K., Moreira, J. C., and di: Medeiros, J. S., 1992, The Amazonia information system. ISPRS Archives, Commission VI, 28, 259-266.

Brondizio, E. S., Moran, E. F., Mausel, $P$, and Wu, Y, 1993, Dinamica na vegetacao do Baixo Amazonas: Analise temporal do uso da terra integrando imagens Landsat TM. levantamentos floristico e etnografico. Proceedings, VII Simpósio Brasileiro de Sensoriamento Remoto (São José dos Campos: Instituto Nacional de Pesquisas Espaciais) pp. 38-46.

Brown, S., and Lugo, A., 1990, Tropical secondary forests. Journal of Tropical Ecolog!: 6, 1-32.

Chomentowski, W., Salas, W., and Skole, D., 1994 Landsat pathfinder project advances deforestation mapping. GIS World, 7, 34-38.

INPE (Instituto NaCional De Pesquisas EsPaCiais), 1992, Deforestation in Brazilian Amazon. Separata (São José dos Campos: Instituto Nacional de Pesquisas Espaciais).

lucas, R. M., Honzak, M., Foody, G. M., Curran, P. J., and Corves, C., 1993. Characterizing tropical secondary forests using multi-temporal Landsat sensor imagery. International Journal of Remote Sensing, 14, 3061-3067.

MARTINI, P. R., 1992, Panamazonia project: an executive report. Revista SELPER, 8, 26--30.

Moran, E. F., Brondizio, E. S., Mausel, P., Li, and Y.H., 1993, Assinaturas espectrais diferenciando etapas de sucessao secundaria no leste Amazonico. Proceedings, Simpósio Brasileiro de Sensoriamento Remoto (São José dos Campos: Instituto Nacional de Pesquisas Espacias, pp. 202-209.

Radambrasil, Projeto, 1978, Folha SC.20-Porto Velho, Levantamento de Recursos Naturais (Rio de Janeiro: Ministério das Minas e Energia, Departamento Nacional da Produção) Mineral).

Schimel, D., Enting, I. G., Heimann, M., Wigley, T. M. L., Raynaud, D., Alves, D., and Siegenthaler, U., 1995, $\mathrm{CO}_{2}$ and the carbon cycle. In Climate Change 1994, Radiatice Forcing of Climate Change and An Evaluation of the IPCC IS92 Emission Scenarios. edited by J. T. Houghton, L. G. Meira Filho, J. Bruce, Hoesung Lee, B. A. Callender. E. Haites, N. Harris and K. Maskell (Cambridge: Cambridge University Press), pp. $35-71$.

Skole, D. L., Chomentowski, W. H., Salas, W. A., and Nobre, A. D., 1994, Physical and human dimensions of deforestation in Amazonia. BioScience, 44, 314-322.

Skole, D. L., and Tucker, C. J., 1993, Tropical deforestation and habitat fragmentation in the Amazon: satellite data from 1978 to 1988. Science, 260, 1905-1910.

Tardin, A. T., Lee, D. C. L., Santos, R. J. R., Assis, O. R., Barbosa, M. P. S., Moreira. M. L., Pereira, M. T., Silva, D., and Santos Filho, C. P., 1980, Subprojeto desmatamento: convênio IBDF/CNPq-INPE. Relatório técnico INPE-1649-RPE/103 (São) José dos Campos: Instituto de Pesquisas Espaciais. 